\title{
Environmental Burden of Charcoal Production and Use in Dar es Salaam, Tanzania
}

\author{
Neema Msuya, Enock Masanja, Abrahamu Kimangano Temu \\ Department of Chemical and Mining, University of Dar es Salaam, Dar es Salaam, Tanzania. \\ E-mail:nmsuya@udsm.ac.tz
}

Received August 15 $5^{\text {th }}, 2011$; revised October 19 ${ }^{\text {th }}, 2011$; accepted November $22^{\text {nd }}, 2011$.

\begin{abstract}
Tanzanian forests are excessively threatened by increased charcoal production fuelled by increased demand crucially in Dar es Salaam city which consumes nearly $70 \%$ of all the charcoal produced in the country. Through use of ecological modeling software STELLA ${ }^{\circledR}$ the environmental burden of charcoal production and use in Tanzania has been established. The study has revealed that the country losses 150,433 ha of forest per year. Due to increase in population by year 2030 almost 2.8 million ha of forests will have been lost. This is equivalent to $8.5 \%$ of the total forest cover the country had in 2009. The environmental burden includes air pollution characterized by a total emission of 49, 1.0, and 9.0, 12 million tonnes of $\mathrm{CO}_{2}, \mathrm{SO}_{2}, \mathrm{NO}_{x}$, and $\mathrm{CH}_{4}$, respectively by 2030. Other adverse impacts include loss of forest cover which ultimately causes degradation of soil quality by increased soil erosion, degradation of water sources and disruption of rainfall pattern including inducing draught. Taking into account that the agriculture in Tanzania is primarily rain fed, this has an adverse impact in agricultural production. In the current exploitation of this important natural resource, its sustainability is severely challenged and the whole concept of the forest being renewable is put into question. From these findings, it is recommended that concrete and deliberate efforts are made to reduce and eventually prohibit the use of charcoal in cities and towns.
\end{abstract}

Keywords: Charcoal Production, Environmental Burden, Forest Loss, Ecological Model

\section{Introduction}

Households in Tanzania generally use a combination of energy sources for cooking that can be categorized as traditional (agricultural residues and fuel wood), intermediate (charcoal and kerosene) or modern (Liquefied Petroleum Gas (LPG), biogas and electricity). Electricity is mainly used for lighting and small appliances like radio, Televisions and phone charging rather than cooking, and represents a small share of total household consumption in energy terms [1]. Over one million tonnes of charcoal is used for cooking annually in Tanzania's urban areas which is equivalent to 109,500 ha of forest loss [2]. Increasing tendency to use charcoal instead of electricity or LPG is driven by availability of charcoal and its presumed low price. The increased consumption of charcoal results in increased forest cover loss. Among the impacts of the forest loss is degradation of water sources, reduction in soil quality and hence decreases in agricultural productivity, damaged habitat, diminishing biodiversity, and reduced sequestration of carbon dioxide by trees. The government tried to institute a ban of charcoal production in 2006 but was largely unsuccessful [3] because no alternative source of fuel was provided.

Different designs of fuel-efficient charcoal stoves that reduce charcoal consumption have been introduced and promoted. These stoves while last longer, are not necessarily user friendly, and are more expensive than the conventional ones. Consequently, their introduction has not changed the rate of consumption of charcoal. Tanzania experienced a loss of forest cover of more than $10.5 \mathrm{mi}-$ llion ha between 1961 and 1998; this represents an annual loss of $0.73 \%$ of forest cover [4]. Charcoal and firewood use alone results in more than $70 \%$ of the forest loss [5], while more than $40 \%$ of the forest loss can be attributed to charcoal use alone [6]. There has been deliberate intervention to redress deforestation by planting trees. Annual tree plantation in the average has been 25,000 ha with a survival of less than $10 \%$ i.e. 2500 ha, which is approximately $2.3 \%$ of the annual forest cover lost. At this rate of loss the concept of forest being a renewable energy resource is threatened.

Charcoal consumption results into about 9 million ton- 
nes of $\mathrm{CO}_{2}$ per year [2]. Dar es Salaam alone use about $70 \%$ of the charcoal produced in the country. The Pugu and Kazimzumbwi forest Reserves within the coastal forests are receiving the brunt of the city's charcoal industry. The only viable mitigation measure is therefore to drastically reduce consumption of charcoal.

\section{Charcoal Production and the Environmental Burden in Tanzania}

Most charcoal is produced from wood, but other sources are possible such as coconut shells and crop residues. Principal charcoal producing areas serving the Dar es Salaam market include five districts in the Coast Region (Kibaha, Kisarawe, Bagamoyo, Mkuranga and Rufiji), two districts in Tanga Region (Kilindi and Handeni), and Morogoro rural district. Main producers in the charcoal market can be classified as: occasional, seasonal and full time.

Full time producers live within the forest areas and produce throughout the year. They only shift when the wood is depleted. Seasonal producers produce only in off-farming period since agriculture is their main occupation. Occasional producers, on the other hand, make charcoal to meet specific cash needs during the year [7].

Charcoal can be produced by either incomplete combustion process or pyrolysis as described by Gomaa and Fathi [8].

Pyrolysis refers the process by heating wood under absence of oxygen in kilns having closed chambers. The incomplete combustion is the basis of this carbonization process through which charcoal is obtained from wood within four consecutive phases. In the firstphase wood loses only water and its external form does not signifycantly change. This occurs at temperatures below $170^{\circ} \mathrm{C}$. Decomposition of wood is the second phase which occurs between $170^{\circ} \mathrm{C}$ and $270^{\circ} \mathrm{C}$. Organic acids and tars are evolved together with water vapour. Also gases like $\mathrm{CO}$ and $\mathrm{CO}_{2}$ are gradually evolved. The third phase takes place between $270^{\circ} \mathrm{C}$ and $350^{\circ} \mathrm{C}$, where wood decomposition proceeds with Evolution of gases and organic liquids at higher rate accompanied with heat. The final phase occurs above $350^{\circ} \mathrm{C}$, where wood decomposition takes place in a smoother manner. During this phase relative amount of $\mathrm{CO}$ and $\mathrm{CO}_{2}$ to $\mathrm{H}_{2}$ and light hydrocarbons goes down as the temperature increases. The process ceases at temperatures between $450^{\circ} \mathrm{C}$ and $550^{\circ} \mathrm{C}$. Above these temperatures the charcoal formed starts to be consumed thus decreasing the yield. In Tanzania most of the charcoal producers use the incomplete combustion method.

\subsection{Charcoal Kilns Types and Efficiencies}

There are mostly two types of kilns used in Tanzania.
These are improved and non improved kilns. Two types of improved kilns are in use, the earth pit and the earth mound. An earth pit kiln is constructed by first digging a small pit in the ground. Then the wood is placed in the pit and lit from the bottom, after which the pit is first covered with green leaves or metal sheets and then with earth to prevent complete burning of the wood. The earth mound kiln is built by covering a mound or pile of wood on the ground with earth, igniting the kiln and allowing carbonization under limited air supply. When Pyrolysis is complete the kiln gradually cools down and the charcoal can be removed from the kiln. The mound is preferred over the pit where the soil is rocky, hard or shallow, or the water table is close to the surface. Mounds can also be built over a long period, by stacking gathered wood in position and allowing it to dry before covering and burning. Mound type is most preferred in Tanzania. Efficiency of kiln and the quality of charcoal varies depending on the construction of the kiln (e.g. walls can be lined with rocks or bricks and external chimneys can be used). Figure 1 shows an example of traditional kilns used in Tanzania. Evidence has shown that with the traditional, unimproved earth kilns, much wood is converted into ash instead of charcoal, the implication of which large amount of logs have to be felled to produce charcoal.

Most kilns in Tanzania have efficiencies ranging from $11 \%-19 \%$ for unimproved kilns while it ranges between $27 \%$ - 30\% for improved type of kilns [7]. During charcoal production nearly a third of the energy is lost due to kiln inefficiencies. Most of charcoal producers in Tanzania however, do not prefer the improved type of kiln due to its high initial investment cost. The traditional earth kilns are preferred as they need very little skill and low capital investment.

\subsection{Impacts of Charcoal Production and Use}

The following are some of the impacts cause due to char-

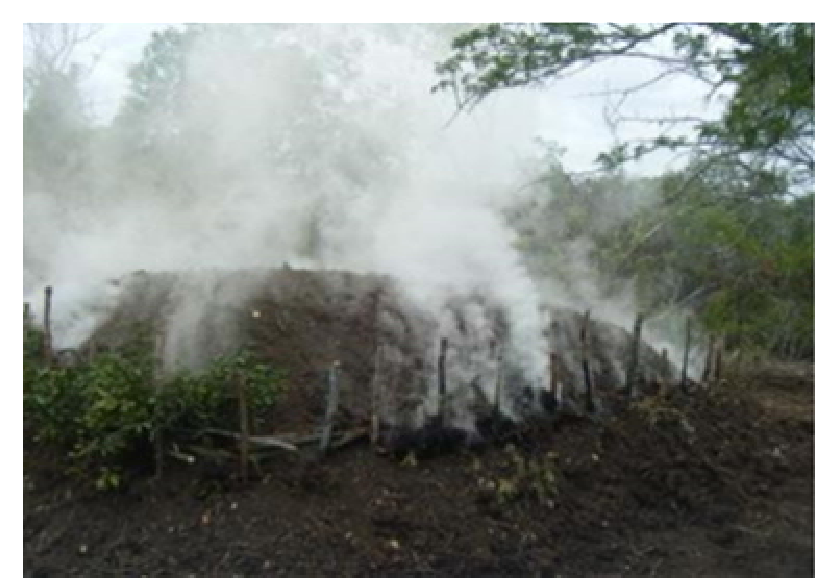

Figure 1. Traditional kiln used in Tanzania. 
coal production and use.

\subsubsection{Deforestation}

Deforestation has been expressed as a gradual loss, mainly by indiscriminate tree felling, of forest and woodland vegetation from a forested and woodlands locality over a period of time. The major causes for deforestation in Tanzania are agricultural expansion, grazing, forest fire, charcoal making and harvesting for timber. Production of charcoal has remarkably become a factor of deforestation in most parts of the Coast region; it contributes about $75 \%$ of the deforestation [9]. Profuse evidence of the charcoal trade is visible throughout Tanzania: a visit to any forest reveals the presence of charcoal makers. Highways are lined with charcoal bags for sale in the production area and on the outskirts of towns.

Thousands of markets throughout the country offer charcoal for sale. Direct environment impact of charcoal production is caused by the felling of trees to produce charcoal. Deforestation disturbs forest ecology by destroying plant and animal habitats. It also destroys species biodiversity and destroys water catchments [10]. Removal of forest vegetation disposes top soil materials and makes them vulnerable to soil erosion by rainfall. As a result soil fertility is decreased and consequently reduced agricultural productivity hence increased poverty. The problems associated with felling trees that are not replaced by regeneration or afforestation activities are well known. These include depletion of water sources and water catchments areas, reduction of carbon sinks; and loss of habitat and biodiversity.

\subsubsection{Environmental Pollution}

Charcoal combustion emits carbon monoxide and nitrogen oxides. In extreme cases, carbon monoxide poisoning leads to brain damage and even death. Nitrogen oxides emissions react with sunlight to produce dangerous air pollution. Fumes from charcoal burning augment those from diesel engines and industrial chimneys [11]. Charcoal consumption makes a small but not negligible contribution to climate change. According to Norconsult [11] the relative contribution of fuel wood and charcoal combustion in emissions is important for $\mathrm{CH}_{4}(46 \%), \mathrm{CO}$ $(42 \%)$, and non-methane hydrocarbons (NMHC) (44\%), but less so for $\mathrm{CO}_{2}(32 \%)$. Health impacts of using charcoal and firewood includes particulates, $\mathrm{CO}, \mathrm{NO}_{2}$, formaldehyde and carcinogens.

\subsubsection{Impact to Rainfall}

Increased charcoal production and use leads to increased cut of trees. This lead into clean land with less tree density, hence reduction on rainy season. Forests play a big role in causing rainfall season therefore destruction of forest is directly proportional to destruction of rain.

\section{Methodology}

An ecological modeling software STELLA ${ }^{\circledR}$ was used in this study to assess the environmental burden of charcoal production and use in Tanzania. The modeling procedure as per Jǿrgensen [12] was as follows:

- Brainstorming: this involved characterization of all factors influencing charcoal production at the site and use;

- Priotization of factors relatively important to charcoal production and use;

- Categorization of factors in state variables, forcing functions and processes as presented in the concepttual diagram, Figure 2; and

- Development of conceptual diagram: the main diagram showing the relationship between the state variables, mass transport from one state variable to the other, which are indicated by arrows, outputs and inputs and the way they are controlled by forcing functions. The process, which is taking place within the system, is also indicated in the conceptual diagram.

The model developed relied on mass balances only. However, one could also do energy balances during charcoal production and use but this study did not. For the purpose of this study: one sack of charcoal weighs $56 \mathrm{~kg}$ while kiln efficiency was taken to be $19 \%$.

\subsection{Mathematical Description}

The Mass flows in and out of each state variable as mathematical descriptions are.

\subsubsection{Kiln Zone State Variable}

The kiln zone state variable has one inflow and four outflows. The change of the amount in this zone can be obtained by the following equation:

$$
\frac{\mathrm{d}(\text { kiln })}{\mathrm{dt}}=\text { wood }-\mathrm{P} 1_{\text {aqueous }}-\mathrm{P} 2_{\text {non }} \text { aqeous }-\mathrm{P} 3_{\text {solids }}-\mathrm{P} 4_{\text {gases }}
$$

where wood is wood to be loaded, $\mathrm{P}_{\mathrm{i}}$ is Pyrolysis products and $\mathrm{i}=1,2,3 \ldots$

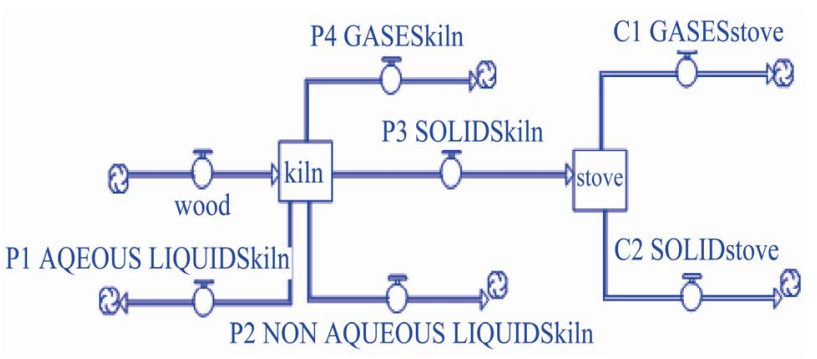

Figure 2. Conceptual diagram for charcoal production and use ( $P$ stands for Pyrolysis while $C$ is for combustion). 


$$
\text { wood }=\mathrm{k} 1 \times \text { Ccons }
$$

where: $\mathrm{C}$ cons is the amount of charcoal consumed in tonnes/year; $\mathrm{k} 1$ is conversion factor for wood to charcoal.

Typical pyrolysis products as percentage of the wood burned are: Gases (56\%), Liquids (25\%) and solids (19\%). In this part the pyrolysis process was separated into four parts, namely: P1 to P4 regarding the outcome/ product of each part and are calculated using the percentages as obtained from the literature as follows:

$$
\begin{gathered}
\text { Liquid Produced }=0.25 \times \text { wood } \\
\text { P1 aqueous }=0.56 \times \text { liquid produced } \\
\text { P2 nonaqueous }=0.44 \times \text { liquid produced } \\
\text { P3 solid }=0.19 \times \text { wood } \\
\text { P4 gases }=0.56 \times \text { wood }
\end{gathered}
$$

\subsubsection{Stove Zone State Variable}

The stove zone state variable has one inflow and two outflows. The change of the amount in this zone can be obtained by the following equation:

$$
\frac{\mathrm{d}(\text { stove })}{\mathrm{dt}}=\mathrm{P} 3 \text { solids }-\mathrm{C} 1 \text { gases }-\mathrm{C} 2 \text { solid }
$$

where;

$$
\begin{aligned}
& \mathrm{C} 1 \text { gases }=0.6 \times \mathrm{P} 3 \text { solids } \\
& \mathrm{C} 2 \text { solid }=0.05 \times \mathrm{P} 3 \text { solids }
\end{aligned}
$$

The total pollution was the sum of the gases from pyrolysis and those from combustion in the stove during charcoal use.

\subsubsection{Translating the Consumption into Hectares of Forest}

The amount of forest needed to produce one sack of charcoal is given by [6]:

$$
\mathrm{Fs}=\mathrm{Ms} \times \mathrm{Ek} \times \frac{1}{\mathrm{~S}}
$$

where: Ms is the mass of a single sack of charcoal [tonnes], Ek is the kiln efficiency [tonnes of wood per tonnes of charcoal], $\mathrm{S}$ is the stock density [tonnes of wood/ha of forest].

\subsection{Data Analysis}

Data on charcoal production and use were obtained from various sources including the Ministry of Natural Resources and Tourism (MNRT-Forest \& Beekeeping Department), Ministry of Energy and Minerals (MEM), Tanzania Traditional Energy Development Organization (TaTEDO), Tanzania Petroleum Development Corporation (TPDC) and ORYX. The data obtained were coupled with the population projections to predict the future de- mand for charcoal in Dar es Salaam. The analysis was done using Excel software. These projections were used as input into the ecological model (STELLA software) to project the wood demand, forest cover loss and the pollution burden to be caused by charcoal consumption and use. The main assumptions made were that household consumption will remain the same throughout from 2010 to 2030 and the population projection of Dar es Salaam will be the same up to 2030 [13].

\section{Results and Discussions}

\subsection{Charcoal Consumption in Dar es Salaam}

The results in Table 1 show that is no consistency in the data on charcoal consumption in Tanzania and Dar es Salaam in particular. The Table shows that for 2009 alone, different sources have quoted different figures ranging from 1600 to 2200 tonnes per day. This could be attributed to the method used during data collection (sample size, season, sampling points, etc.), population data used and the average weight per sack as the sacks are of different sizes. For this study the average of them was used.

\subsection{Forest Loss Due to Charcoal Production and Use}

There are many published estimates of the scale of Tanzanian deforestation. Table 2 gives some of the estimates. The forest loss in Tanzania has been reported to be $0.73 \%$ between 1961 and 1998 [4]. Table 2 indicates that there

\begin{tabular}{|c|c|c|c|c|}
\hline$\overline{\text { Year } 1}$ & Dar population [13] & Number of bags & Charcoal in tonnes & $\overline{\text { Source }}$ \\
\hline 2009 & $2,961,000$ & 28,857 & 1616 & {$[14]$} \\
\hline 2009 & $2,961,000$ & 33,125 & 1855 & {$[15]$} \\
\hline 2009 & $2,961,000$ & 40,000 & 2240 & {$[16]$} \\
\hline
\end{tabular}
is significant forest cover loss due to charcoal production and use; a situation if not arrested could be disastrous.

\subsection{Modeling Results}

The results from the model have been characterized in three categories; these are projected charcoal demand, projected forest loss and pollution burden.

Table 1. Dar charcoal consumption/day as obtained from different sources.

Table 2. Forest covers loss in Tanzania.

\begin{tabular}{ccc}
\hline Year & Forest Loss (ha) & Source \\
\hline 2004 & 91,000 & {$[17]$} \\
2005 & $130,000-500,000$ & {$[1]$} \\
2007 & $130,000-500,000$ & {$[3]$} \\
2008 & 92,000 & {$[18]$} \\
2008 & 109,500 & {$[2]$} \\
\hline
\end{tabular}




\subsubsection{Projected Charcoal Demand}

The projected charcoal demand was used as the basis for the projections for wood needed the forest cover to be lost, and the pollution to be caused during charcoal production and use. The average charcoal consumption in Dar es Salaam (based on 2009 data) was 1904 tonnes/day, equals to 694,960 tonnes per year. Using this charcoal consumption as the basis, the projection for the charcoal demand for the next 20 years was modelled by STELLA with respect to population growth and the result is shown in Figure 3.

Data in Figure 3 shows the graph of population projection trend by NBS [13]. Only twenty years to come (in 2030) the projection shows that more than 18 million tonnes of charcoal will be consumed in Dar es Salaam. This is when the population will be 4,469,297 people.

\subsubsection{Projected Forest Loss}

The results from the model show that 105,303 hectares of forest were lost due to charcoal consumption in Dar es Salaam in 2009. This is equivalent to 150,433 hectares of forest loss due to charcoal use nationwide, which is within the range provided by WWF [3] and Kilahama [1] in Table 2. Figure 4 shows the projection of forest cover which will be needed (or lost) to fulfill the demand for charcoal in Dar es Salaam. The assumptions made were: Household consumption will remain the same throughout till 2030 and the population projection of Dar es Salaam will be the same as per NBS [13].

In total more than 2.8 million hectares of forest should be destroyed from 2010 to 2030 to fulfill the demanded charcoal for Dar es Salaam alone, resulting into more than 4.0 million hectares nationally. If this is amortized in those 20 years; Tanzania has to lose 140,000 ha annually only for Dar charcoal market which is equal to 200,000 ha nationwide. Based on the value of USD 1500/ha of forest [11] charcoal consumption in Dar es Salaam will be causing a loss of about USD $210 \mathrm{~m}$ per year which is equal to USD $300 \mathrm{~m}$ nationally, and this is about $1.5 \%$ of

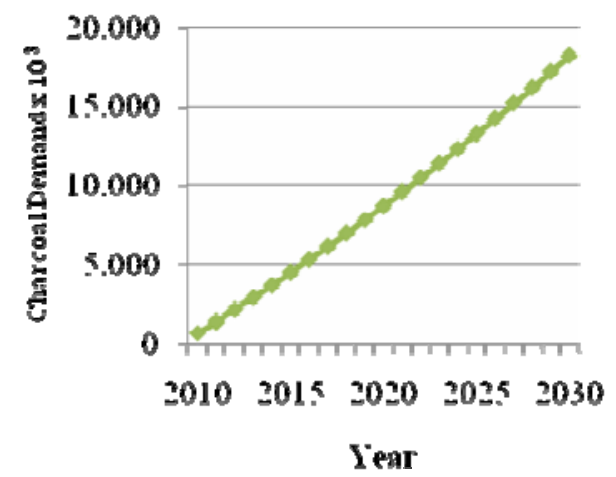

Figure 3. Projected charcoal demand for Dar es Salaam.

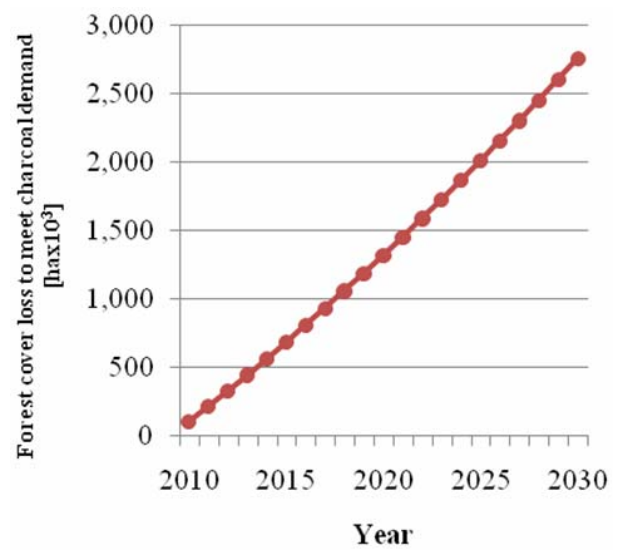

Figure 4. Forest cover required to fulfill charcoal demand in Dar es Salaam.

the current GDP.

\subsubsection{Pollution Burden}

Among the major effects of charcoal production and use is the pollution burden to the environment as shown in Figure 5. The results show that charcoal production and use will result into a total of 49.7 million tonnes of $\mathrm{CO}_{2}$ up to 2030. This is a disaster not only to human health, but also to environment and other creatures. The higher the production rate for charcoal the higher the removal of trees and at last no carbon sink. As shown in Figure 5; the $\mathrm{CO}$ which will be emitted by 2030 and be absorbed in atmosphere is more than 20 million tonnes. This is with the assumption that half of the $\mathrm{CO}$ produced is not stable and is converted to carbon dioxide immediately; otherwise the amount could be more than this. $\mathrm{CO}$ poisoning leads to brain damage if inhaled. Most of the trees used for charcoal production contain some percentage of sulphur and this is the source of $\mathrm{SO}_{2}$. Poor design and construction of the kilns and charcoal stoves result into impossibilities to control air during charcoal production and

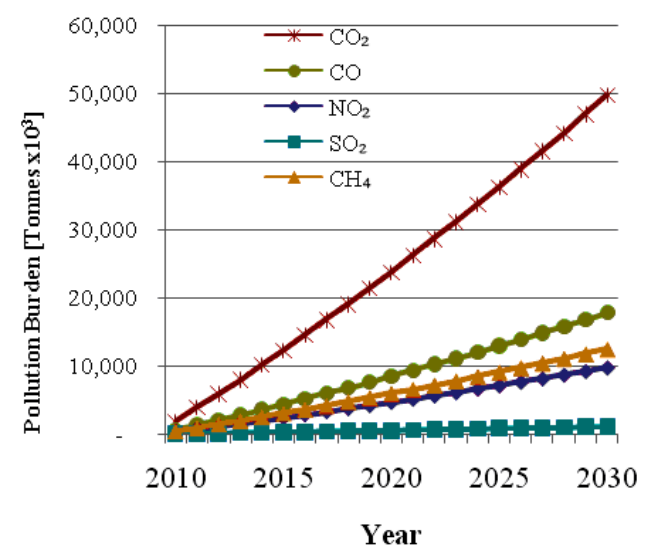

Figure 5. Projections for gas emissions due to charcoal production and use. 
use and this is the source of $\mathrm{NO}_{2}$ in the produced gases. The higher the production and use, the higher these gases are produced. A total of 9,830,561, 1,109,762 and 12,478, 260 tonnes of $\mathrm{NO}_{2}, \mathrm{SO}_{2}$ and $\mathrm{CH}_{4}$, respectively will be produced by 2030 only by continuing producing and using charcoal in Dar es Salaam as shown in Figure 5.

\section{Conclusions}

From the analysis, more than 2.8 million ha of forest will be cut to fulfill the demanded charcoal for Dar es Salaam alone. Not only that but also the process of producing and using this amount of charcoal has huge impact to the environment as measured by the amount of gases which will result and emitted to the atmosphere. Charcoal production and use will result into about 2.5 tonnes of $\mathrm{CO}_{2}$ annually, making a total of 49.7 million tonnes of $\mathrm{CO}_{2}$ up to 2030 . This is a disaster not only to human health, but also to environment 9 and other creatures. The higher the production rate for charcoal the higher the removal of trees and at last no carbon sink. Because of inefficiency of the kilns and charcoal stoves a total of 20 million tonnes of CO will be released to the atmosphere up to 2030 . This is unhealthy given its poisoning potential. Other gases resulting from production and use of charcoal in Dar es Salaam are 9,830,000, 1,109,000 and 12,478,000 tonnes of $\mathrm{NO}_{2}, \mathrm{SO}_{2}$ and $\mathrm{CH}_{4}$ respectively.

The observed high level of methane produced calls for appropriate technology to capture and re-use it as a natural gas. Some of these gases might lead into acid rain. There is therefore, an urgent need to reduce pressure on forests through advocacy of affordable and more environmental friendly alternative sources of energy for cooking in Tanzania.

\section{REFERENCES}

[1] F. Kilahama, "Impact of Increased Charcoal Consumption to Forest and Woodlands in Tanzania," 2005. http://www.coastalforests.tfcg.org/pubs/Charcoal\&Forest s.pdf

[2] TaTEDO, "Charcoal Industry in Tanzania with Selected TaTEDO Experience," Sustainable Energy and Development Forum: Newsletter, No. 7, 2009, p. 8.

[3] WWF, "A Project Proposal to Begin Resolving the Environmental Crisis Caused by Charcoal the Dar Charcoal Project," Ministry of Natural Resources Tanzania, 2007.

[4] MNRT, "The National Forest Programme in Tanzania 2001-2010," Forest and Beekeeping Division, Dar es Salaam, 2001, p. 111.
[5] E. Zahabu and R. E. Malimbwi, "Impact of Charcoal Extraction on the Miombo Woodlands, the Case of Kitulangalo Area; Tanzania," Sokoine University of Agriculture, Sokoine, 2001, Unpublished MSc.

[6] T. H. Mwampamba, "Has the Wood Fuel Crisis Returned? Urban Charcoal Consumption in Tanzania and Its Implications to Present and Future Forest Availability," 2007. http://www.charcoalproject.org/wp-content/uploads/2011/ 01/Mwampamba-2007-Charcoal-Tanzania.pdf

[7] CHAPOSA, "Charcoal Potential in South Africa," Final Report, Stockholm Environmental Institute, International Cooperation with Developing Countries EU INCO_DEV Project, 2002.

[8] H. Gomaa and M. Fathi, "A Simple Charcoal Kiln for Hardwoods or Other Dense Biomass (Quick, Efficient, Economic with Low Environmental Impact," Cairo University, Cairo, 2000, pp. 167-174. http://virtualacademia.com/pdf/clea167_174.pdf

[9] R. E. Malimbwi and E. Zahabu, "Contribution of Charcoal Extraction to Deforestation" Experience from CHAPOSA Research Project," 2005.

http://coastalforest.tfcg.org/pubs/Char_Deforestation_CH APOSA.pdf

[10] R. Minja, "The State of Tree Cutting and Charcoal Burning in Mkuranga District," A Study on Environmental Concern in Mkuranga District, 2006. http://coastalforests.tfcg.org/pubs/Char_Mkuranga.pdf

[11] Norconsult, "The True Cost of Charcoal: A Rapid Appraisal of the Benefits of Substituting LPG for Charcoal as an Urban Fuel in Tanzania," 2002.

http://coastalforests.tfcg.org/pubs/NORConsult_charcoal_ vs_LPG.pdf

[12] S. E. Jǿrgensen, "Use of Models as Experimental Tool to Show Structural Changes Accompanied by Increased Energy," Ecological Modeling, Vol. 41, 1988, pp. 117-126. doi:10.1016/0304-3800(88)90049-X

[13] NBS, "Population and Housing Census," National Bureau of Statistics, Dar es Salaam, 2002

[14] I. Mani, "The Price of Using Charcoal in Town," 2009. http://allafrica.com/stories/200911181056.html

[15] WWF, 2009. "Charcoal and Deforestation across East Africa” Press Release. http://www.worldwildlife.org

[16] Tanzania Petroleum Development Center, "Use Natural Gas to Conserve the Environment, Brochure," Dar es Salaam, 2009, p. 4.

[17] Ministry of Energy and Minerals, "Baseline Study on Biomass Energy Conservation in Tanzania," SADC Programme for Biomass Energy Conservation (ProBEC), 2004.

[18] MNRT, "Forest Cover Loss in Tanzania," Forest and Beekeeping Division, Dar es Salaam, 2009. 